\title{
The Effects of Steroids on the Human Lens Epithelium
}

\author{
T. J. C. JACOB, A. K. A. KARIM and G. M. THOMPSON \\ London
}

\begin{abstract}
Summary
A study of anterior capsules from cataractous lenses revealed that there are marked abnormalities in epithelial structure associated with cataract. In certain cases a distinctive reticulated pattern was observed in whole mounts of the anterior capsule and of these a higher number than expected were from patients receiving steroid medication. In tissue culture experiments it was found that the presence of steroids in the growth medium $(10 \mu \mathrm{M}$ prednisolone) adversely affected the growth of human lens epithelial cells.

These observations are consistent with the hypothesis that steroid-induced cataracts are the result of effects on anterior lens epithelial cell function.
\end{abstract}

Steroids are thought to induce cataract. ${ }^{1}$ This study was undertaken to test the hypothesis that steroids cause cataract by interfering with the normal functioning of the anterior lens epithelium.

\section{Material and Methods}

Human anterior capsules with adherent epithelial cells were obtained from clear, normal human lenses removed from fresh $(<48$ hours post mortem) donor eyes used for corneal transplantation. Lenses showing any cataractous changes were discarded.

Anterior capsules from cataractous lenses were obtained during extracapsular cataract surgery. Pre-operatively, data concerning the patient's medical history were collected, and details of steroid medication (if any) recorded.

The patient was examined by slit-lamp biomicroscopy and the morphology of the cataract recorded. The type and extent of the cataract were classified as described by Karim, Jacob and Thompson.?

Surgery was performed using a standardised technique by the same surgeon in all cases. A superior ab externo incision was made of partial thickness at the limbus and the anterior chamber filled with Healonid through a small paracentesis. Capsulotomy was performed using a bent 23-gauge Brunswick needle. The lens capsule was divided by multiple small perforations just within the line of insertion of the zonules. The central capsule was removed in one piece with a pair of plain blocked forceps, the circular capsule (approximate diameter $6 \mathrm{~mm}$ ) was then placed in Dulbecco's phosphate buffered saline.

The specimen of anterior capsule was spread on a poly-l-lysine coated microscope slide and fixed with Karnovsky's fixative (diluted to physiological osmolarity). After air drying, the specimen was stained with toluidine blue, washed with distilled water and dehydrated through graded alcohols finishing with xylene. The specimen was then mounted (DPX) and cover-slipped.

For tissue culture, normal lens epithelial tissue was obtained from human donor eyes used for corneal graft surgery within 48 hours of death of the donor. The eye was bisected equatorially behind the ora serrata and the lens removed by cutting the suspensory ligaments. Details of the explant technique and method of cell counting have been described previously. ${ }^{3}$ The explants were cultured

From: The Eye Group, St George's Hospital Medical School, Tooting, London SW17 0RE.

Correspondence to: T. J. C. Jacob, PhD, Department of Pharmacology, St George's Hospital Medical School, Cranmer Terrace, London SW17 0RE.

Presented at the Annual Congress of the Ophthalmological Society of the United Kingdom, April 1987. 
in medium E199 with fetal calf serum (FCS), 50 per cent for the first 10 days, reduced to 36 per cent on day 10,25 per cent on day 13,10 per cent on day 16 and thereafter the cells were re-fed every three days with E199+10 per cent FCS. No antibiotics or antimycotics were used. The cultures were placed in a humidified, gassed ( 5 per cent $\mathrm{CO}_{2}$ ) incubator and maintained at 37 degrees $C$. The outgrowth of cells was measured at specified intervals using a calibrated eyepiece graticule and phase contrast optics, and the number of cells determined as described previously. ${ }^{3}$

\section{Results and Discussion}

In the normal human lens the cells of the anterior epithelium exhibit a regular, hexagonal morphology with no visible intercellular spaces under light microscopy. The uniformity of both the cellular array and the degree of uptake of stain were most marked (Fig. 1). The density of cells increased from 4,450 cells/ $\mathrm{mm}^{2}$ in the central region to 5,500 cells $/ \mathrm{mm}^{2}$ in the equatorial region, reflecting the radial decrease in cell size. ${ }^{2}$ In epithelia from normal lenses no significant changes were observed with ageing over the age range 23 to 84 years.
However it should be mentioned that some "normal" lenses from donors over 70 years old, with no history of visual impairment, had cortical opacities off the visual axis. The epithelia from these lenses exhibited the morphological features (often only peripherally) associated with cortical cataract (see below).

Distinct abnormalities in cell morphology, size and density have been observed in cataractous epithelia $;^{2}$ in particular in those cataracts involving cortical and/or posterior subcapsular opacities. Karim et al. ${ }^{2}$ reported a significant decrease in cell density in these groups of cataractous epithelia due to the extensive appearance of enlarged cells. Figure 2 shows a whole mount of the epithelium from a lens with posterior subcapsular cataract (PSC). There is evidence of cell swelling, a disturbance to the regular hexagonal array and a non-uniformity of staining. Enlarged, non-staining cells were observed in 45 per cent of the cataractous epithelia studied by light microscopic examination of toluidine blue stained whole mounts. The absence of the basophilic stain toluidine blue in these

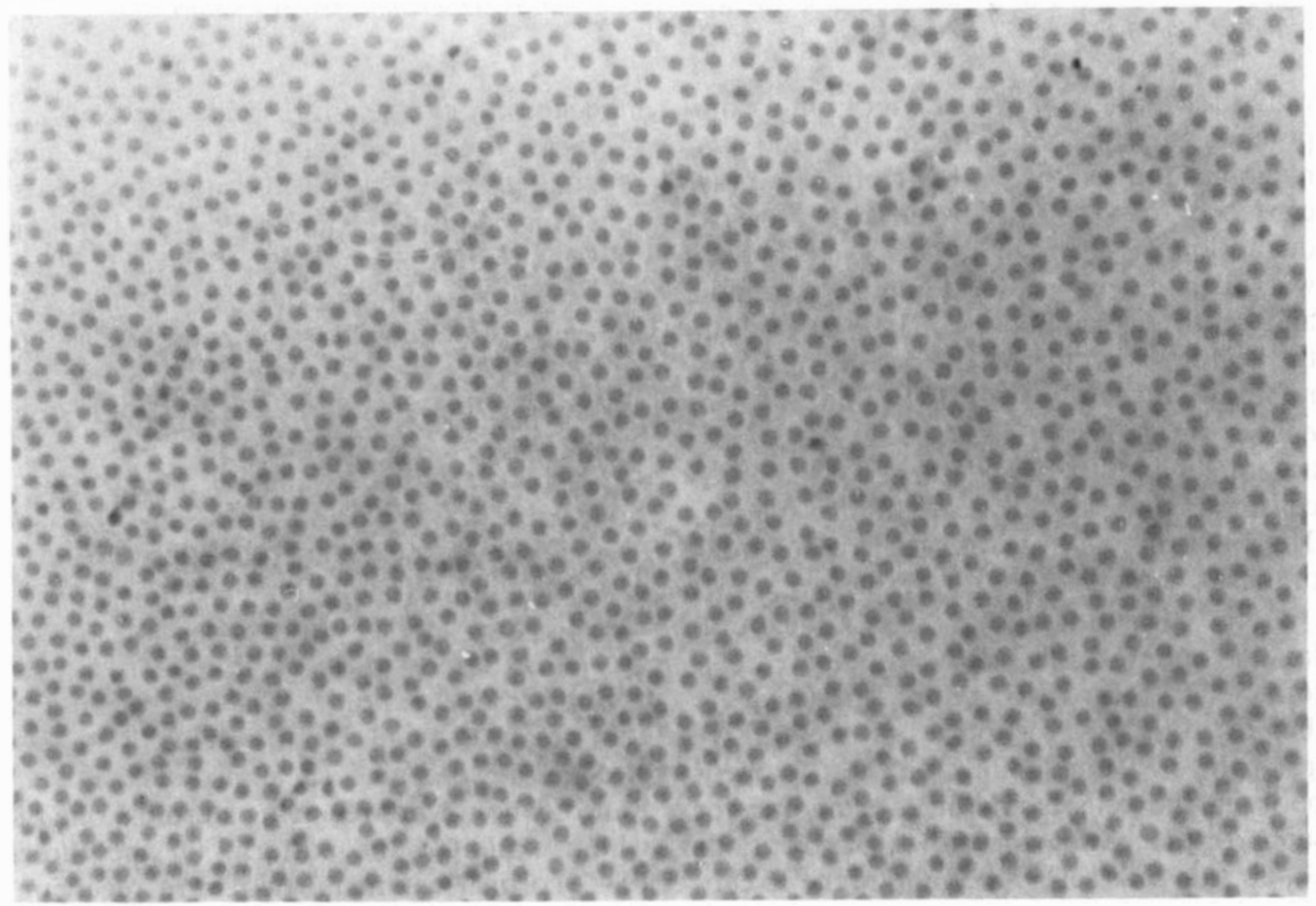

Fig. 1. Whole mount of an anterior capsule from a normal human lens, stained with toluidine blue, from a 63 year old donor eye (field width $1.1 \mathrm{~mm}$ ). 


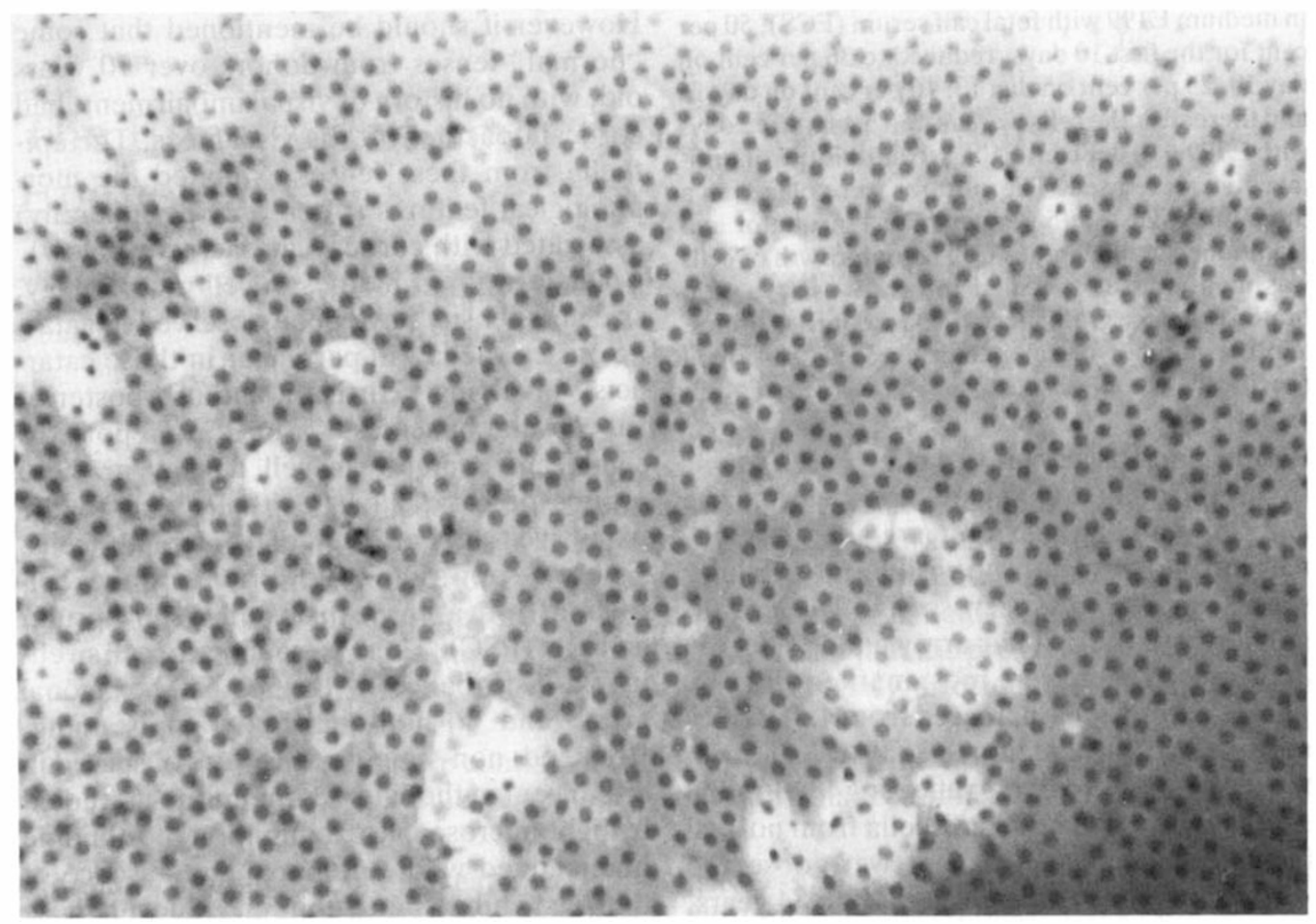

Fig. 2. Whole mount of a capsule from a lens with cortical and posterior subcapsular cataract, stained with toluidine blue (field width $1.1 \mathrm{~mm}$ ).

cells indicates the loss of cytoplasmic components and this may be due to the permeabilisation of the cell membrane either caused by or resulting in cell swelling. The disruption of the regular hexagonal pattern was observed in most cataractous epithelia and was often confined to small regions within the epithelium, there being no apparent correlation between loss of this regular hexagonal pattern with cataract type. Often accompanying the appearance of enlarged cells, were intercellular clefts and vacuoles. The 13 normal lenses studied exhibited none of these characteristics.

Of the 41 cataractous epithelia studied thus far, 15 exhibited a distinctive reticulated pattern. This pattern, two examples of which are illustrated in Fig. 3, is the result of extensive intercellular uncoupling. Gaps appear between the cells, sometimes extending for some distance, leaving fibrous projections connecting cells across the gap. Of the 15 capsules exhibiting this pattern, a higher number than expected (11) were from patients receiv- ing steroid medication. The proportion, $11 / 15$, of those lens epithelia exhibiting the reticulated pattern to those cataract patients receiving steroids, compares with $4 / 26$ for those exhibiting the reticulated pattern in the non-steroid group. On the basis of the chisquared test there was a significant correlation $\left(\mathrm{P}=0.0002 ; x^{2}=13.77\right)$ between the appearance of the reticulated pattern and the taking of steroids.

The relationship between posterior subcapsular cataract (PSC) and steroid medication has been well established ${ }^{4.5}$ (and see Ref 1 for a review). In our study, seven patients were classified as having pure PSC, three were receiving steroids and all exhibited the reticulated pattern shown in Fig. 3. PSC was more commonly associated with nuclear sclerosis and there were nine such mixed cataracts, four of whom were receiving steroids, one of whom exhibited the pattern. Of the three PSC+cortical cataracts, two were receiving steroids and both exhibited the pattern. The largest group of cataracts were those from 

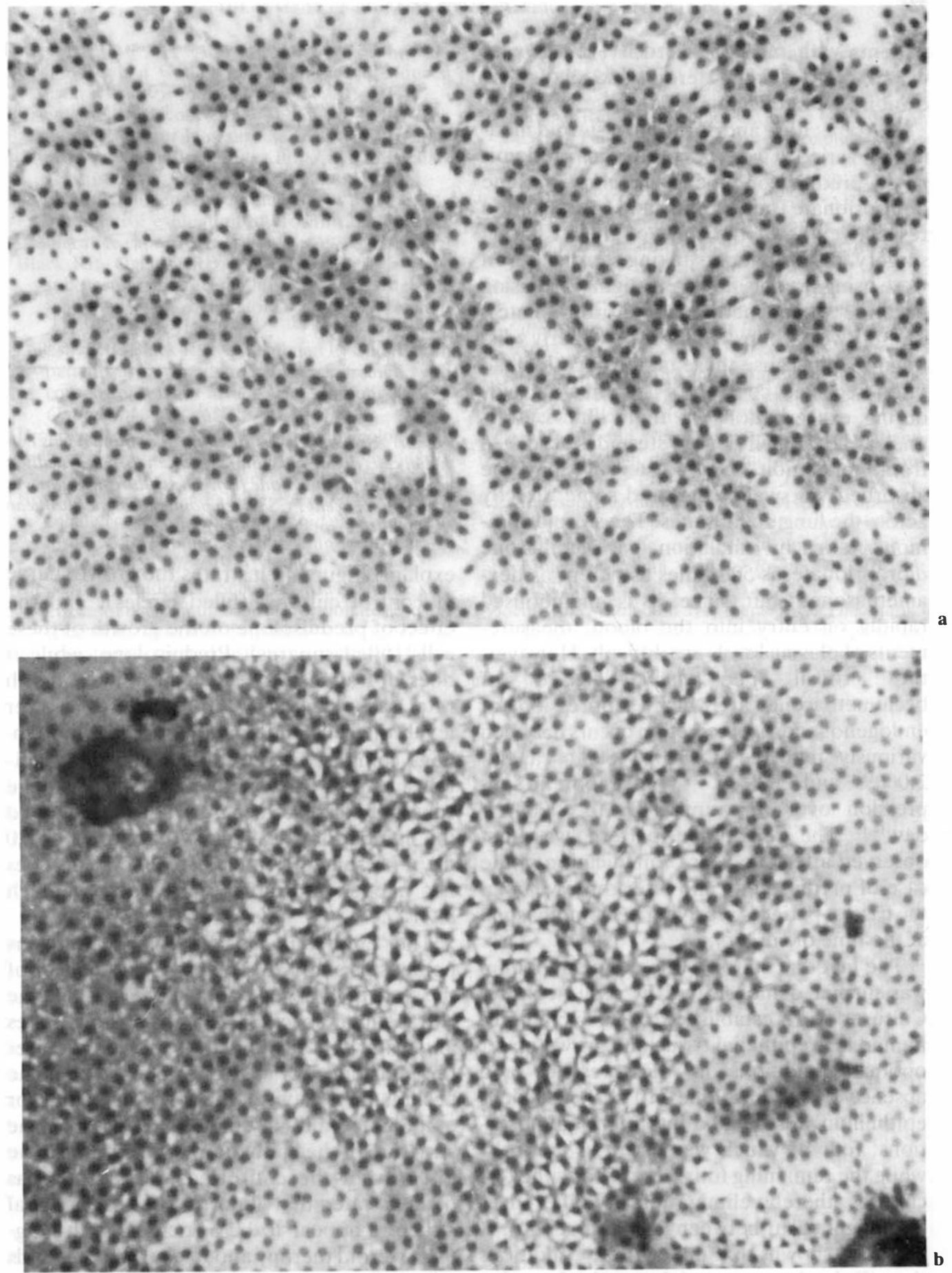

Fig. 3.

(a) Whole mount of an anterior capsule from a lens with posterior subcapsular cataract. Note the reticulated pattern. This patient had a three year history of steroid medication. Stained with toluidine blue (field width $1.1 \mathrm{~mm})$.

(b) Whole mount of an anterior capsule from a steroid cataract illustrating another manifestation of the reticulated pattern shown in Fig. 3(a). Stained with toluidine blue (field width $1.1 \mathrm{~mm}$ ). 
patients with nuclear sclerosis (16), five of whom were receiving steroids and all of these exhibited the reticulated pattern.

The type, dose and duration of steroid medication varied. Two types of steroids predominated-prednisolone and beclomethasone diproprionate (taken orally and by inhalation respectively). At the time of their cataract surgery, of our patients taking steroids seven were using prednisolone and eight were using becotide (beclomethasone diproprionate). These two groups cannot be clearly distinguished because those taking becotide had often received courses of systemic steroids during exacerbations of their illness. It is unclear how much (if any) steroid is absorbed from inhalation. Some steroid may be absorbed via swallowing, and some directly across the lung membranes. The steroid commonly taken by inhalation, beclomethasone diproprionate, is 500 times as potent as dexamethasone ${ }^{6}$ but since it is metabolised rapidly on entry into the blood, measurements of plasma levels are difficult. However, the critical per diem dosage of beclomethasone at which suppression of endogenous cortisol secretion occurs has been variously reported as $400,,^{7.8} 800,{ }^{9} 1,600,{ }^{10}$ $2,000^{11,12}$ and 3,000 $\mu \mathrm{g} .{ }^{13}$ Others report no suppression over the range 400 to $2,000 \mu \mathrm{g} /$ day. ${ }^{14.15}$ The reticulated pattern was first observed after one year of medication in the case of prednisolone and after three years in the case of patients receiving beclomethasone at the time of surgery.

The fact that steroids effect the epithelium was further demonstrated by tissue culture. Cultures were established from explants of human lens epithelial tissue and grown under optimal conditions in the presence and absence of prednisolone $(10 \mu \mathrm{M})$. The lens epithelium was divided into eight equal sections, four of which were used as controls, while the remaining four were used as the test cultures, thereby eliminating any differences that might occur between lenses (e.g. age). It has been shown ${ }^{3}$ that under these conditions the cells begin exponential growth after a lag period of 2-3 days. They undergo 4-6 population doublings before cell proliferation ceases. At this point the outgrowth extends some $5 \mathrm{~mm}$ from the edge of the original

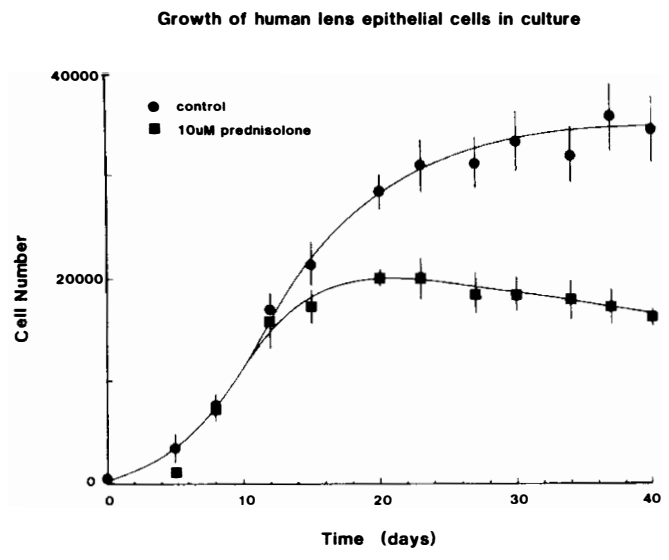

Fig. 4. Growth curves for cultures of human lens epithelial cells in normal culture medium (O) and medium with $10 \mu \mathrm{M}$ prednisolone ( $\mathbf{\square})$. The culture medium was E199+10 per cent FCS. Each point represents the mean ( \pm standard error) of 4 cultures.

explant. Figure 4 illustrates the growth curve of control cultures (filled circles), and the effect of prednisolone on the growth of these cells (filled squares). Prednisolone, while it does not appear to effect the initial growth rate, causes the curve to plateau at a lower level; the cells undergo 4.6 population doublings compared to 5.4 under control conditions. And, further to this, prednisolone causes the cells to senesce more rapidly and the number of cells begins to decline after 20 days, presumably due to cell death. This does not happen in control cultures until much later.

The epithelium is responsible for lens homeostasis and this involves the control of the state of hydration of the fibre cells and the extracellular space. ${ }^{6}$ The transport of solutes and water that facilitate this process requires the existence of tight junctions (zonulae occludentes) between the cells of the anterior epithelium and anything that disturbs the structure of the epithelium will jeopardise the integrity of the entire lens. This study has demonstrated that abnormalities in epithelial structure appear to be associated with longterm steroid therapy and further, that steroids adversely the growth of these cells in culture.

We would like to thank the Visual Research Trust, the Human Research Trust and St George's Hospital Research Committee for their support of this work. T.J.C.J. is an MRC Senior Fellow. 


\section{References}

${ }^{1}$ Urban RC and Cotlier E: Corticosteroid-induced cataracts. Surv Ophthalmol 1986, 31: 102-10.

${ }^{2}$ Karim AKA, Jacob TJC, Thompson GM: The human anterior lens capsule; cell density, morphology and mitotic index in normal and cataractous lenses. Exp Eye Res 1987, 45: 93-104.

${ }_{3}^{3}$ Jacob TJC: Human lens epithelial cells in culture: a quantitative evaluation of growth rate and proliferative capacity. Exp Eye Res 1987, (in press).

${ }^{4}$ Black RL, Oglesby RB, von Sallman L: Posterior subcapsular cataracts induced by corticosteroids in patients with rheumatoid arthritis. J Am Med Ass 1960, 174: 166-71.

${ }^{5}$ Oglesby RB, Black RL, von Sallman L: Cataracts in patients with rheumatic diseases treated with corticosteroids. Further observations. Arch Opthalmol 1961, 66: 625-30.

${ }^{6}$ Brogden RN: Inhaled steroids: pharmacology and toxicology. In TJH Clark, Ed., Steroids in Asthma. Adis Press, Auckland, 1983, 121-34.

${ }^{7}$ British Thoracic and Tuberculosis Association: Inhaled corticosteroids compared with oral prednisolone in patients starting long-term therapy for asthma. Lancet 1975, i: 469.

${ }^{8}$ Messerli C, Studer H, Scherrrer M: Systemic side effects of beclomethasone diproprionate aerosols (becotide, aldecine, sanasthmyl) in otherwise non-steroid treated asthmatic patients. Pneumonologie 1975, 153: 29-42.
${ }^{9}$ Mygind $\mathrm{N}$ and Hansen I: Beclomethasone diproprionate aerosol effect on the adrenals in normal persons. Acta Allergol 1973, 28: 211-8.

10 Gaddie J, Reid IW, Skinner C, Petrie GR, Sinclair DJM, Palmer KNV: Aerosol beclomethasone diproprionate: A dose-response study in chronic bronchial asthma. Lancet 1973, ii: $280^{\circ} 1$.

"Choo-Kang YFJ, Cooper EJ, Tribe AE, Grant IWB: Beclomethasone diproprionate by inhalation in the treatment of airways obstruction. $\mathrm{BrJ}$ Dis Chest 1972, 66: 101-6.

${ }^{12}$ Harris DM, Martin LE, Harrison C, Jack D: The effect of oral and inhaled beclomethasone diproprionate on adrenal function. Clin Allergy 1973, 3: 243-8.

${ }^{13}$ Harris DM: Properties and therapeutic uses of some corticosteroids with enhanced topical potency. $J$ Steroid Biochem 1975, 6: 711-6.

${ }^{14}$ Costello JF and Clark JN: Response of patients receiving high dose beclomethasone diproprionate. Thorax 1974, 29: 571-3.

15 Lahdensuo A, Alanko K, Poppius H, Harkonen M: A comparative study of the efficacy of inhaled beclomethasone and systemic prednisolone in bronchial asthma. Scand J Respir Dis 1974, 55: 309-19.

16 Jacob TJC, Bangham JA, Duncan G: The characterisation of a cation channel on the apical surface of the frog lens epithelium. Quart $J$ Exp Physiol 1985, 70: 403-21. 